\title{
Water Quality Performance of In-Series BMPs
}

\author{
Mauricio Carvallo Aceves, Musandji Fuamba and Jessica Angui \\ Polytechnique Montréal, Montréal, Québec.
}

\begin{abstract}
The need to provide adequate water quality control using best management practices (BMPs) requires accurate modeling in order to determine their ideal placement within the watershed. A case study in the Montréal area used PCSWMM software to analyse the implementation of green roofs, rain gardens, pervious pavement and vegetative swales, individually as well as in possible combinations, by comparing both outfall hydrographs and pollutant removal rates to assess the performance of each alternative. Of the individual BMPs, rain gardens provided the highest levels of runoff control, with slight performance improvements when they were coupled in series with green roofs, but with lower performance when adding pervious pavements. The overland flow path could significantly affect which pollutants were picked up by runoff, but to accurately model complex buildup and washoff processes requires information that might not be readily available for all watersheds. Even though the results can be highly case specific, the results obtained highlight the limitations still faced by water-resources professionals, and raise important points that challenge common conceptions regarding BMP implementation. More data on real life performance over long periods of time is still needed to better analyse BMP combinations.
\end{abstract}

\section{Introduction}

The implementation of stormwater best management practices (BMPs) could significantly help to re-establish the natural hydrological cycles of sites affected by urban development and land-use modification. Different processes, such as infiltration, interception and absorption, among others, may provide quantitative control (by reducing runoff speeds, flows and volumes) as well as qualitative control for stormwater (Cahill 2012; Ahiablame et al. 2012). Over recent years, more and more cities have drafted manuals and codes to describe where and how to implement the different practices (i.e. green roofs, infiltration trenches, and suchlike) according to specific water quality and quantity control objectives, thus guiding land planners and engineers in the overall design process (GVSDD 1999; DEP 2006; TRCA 2010; MDDELCC 2011). Due to the different technical constraints and because the level of control provided may vary greatly between BMPs, there is no single alternative (or combination) best suited for all cases, presenting the challenge of finding the option that best responds to the site specific characteristics of the watershed. As such, researchers have given significant attention to the choice and placement of BMPs and have approached the problem in many different ways.

One such approach is to consider multi-criteria evaluation, as described by Jia et al. (2013), Fuamba et al. (2011) and Martin et al. (2007), to rank the different alternatives based on specific criteria and priorities. Since economic cost tends to be a limiting factor in development projects, other researchers have focused on the development of optimization algorithms aimed at providing a certain level of flow control at minimum capital cost, such as the work done by Maringanti et al. (2011), Chen et al. (2015) and Zou et al. (2015). Nevertheless, the objectives of these studies tended to be associated exclusively with quantitative flow control. Thus there has been relatively little work on possible pollutant removal rates, especially when considering in-series BMPs. Sebti et al. (2016) included the water quality constraint in an optimization algorithm for BMP sizing and placement using linear programming, the genetic algorithm and simulated annealing. However, this constraint was directly associated with the interceptor capacity (responsible for conveying the flow to the treatment station), ultimately reducing the said constraint to a quantitative one, without analysis of the treatment actually performed by the individual practices.

More recently, Dai et al. (2016) analysed optimal BMP placement in a watershed in China in order to keep discharges from various pollutants under an acceptable limit. While successfully incorporating data uncertainty, the actual hydrological simulation was kept relatively simple, estimating annual pollutant discharges based on land use runoff coefficients and the capacity of the different BMPs to provide treatment. Pollutant transportation during a given rain event remained outside the study. On the other hand, Hathaway and Hunt (2009) evaluated the performance of a real BMP setup consisting of three wetlands in series. They analysed how the concentrations of different pollutants developed as the flow passed through several key points in the system. Their results showed that most of the treatment is achieved in the first wetland (with little contribution from further downstream), and that there was a possibility of pollutant leaching in some cases. However, their conclusions were restricted to the results of the analysis of in-series implementations of similar BMPs (only wetlands), and they did not explore the possible interaction of different BMPs that might be more commonly found in urban watersheds.

Carvallo Aceves, M., M. Fuamba and J. Angui. 2017. Water Quality Performance of In-Series

BMPs. Journal of Water Management Modeling 26:C430. https://doi.org/10.14796/JWMM.C430

(c) CHI 2017. www.chijournal.org ISSN 2292-6062. 
Carvallo Aceves and Fuamba (2016) applied different multi-criteria decision aid methods to analyse four different BMPs and their possible combinations. Due to the limited information available for the site their work served only as a preliminary approach to rank the different alternatives, with the results suggesting that the addition of supplementary practices in series may not necessarily lead to higher pollutant removal rates, and that further research was needed on the matter.

This study continues the same line of work. We analyse in more detail the possible flow paths followed by stormwater as it passes from one BMP to another, and evaluate the overall pollutant removal rates by focusing on two main aspects: the impact of serial combinations of BMPs and comparison of the outfall hydrographs.

\section{Methodology}

A hydrological model of a previous case study was created to test the effect of different flow paths in an urban watershed. Located in the Greater Montréal area, the case study's main characteristics (the schematic is shown in Figure 1) were presented by Carvallo Aceves and Fuamba (2016). The site consists mainly of a low density residential area, with a park and a school near the upstream end of the watershed. Since this area presented the greatest potential for the successful installation of BMPs and variously combining them, this study focuses solely on it. This particular zone is located over relatively flat terrain at an elevation of $\sim 15 \mathrm{~m}$, draining an area of $\sim 2.15$ ha.

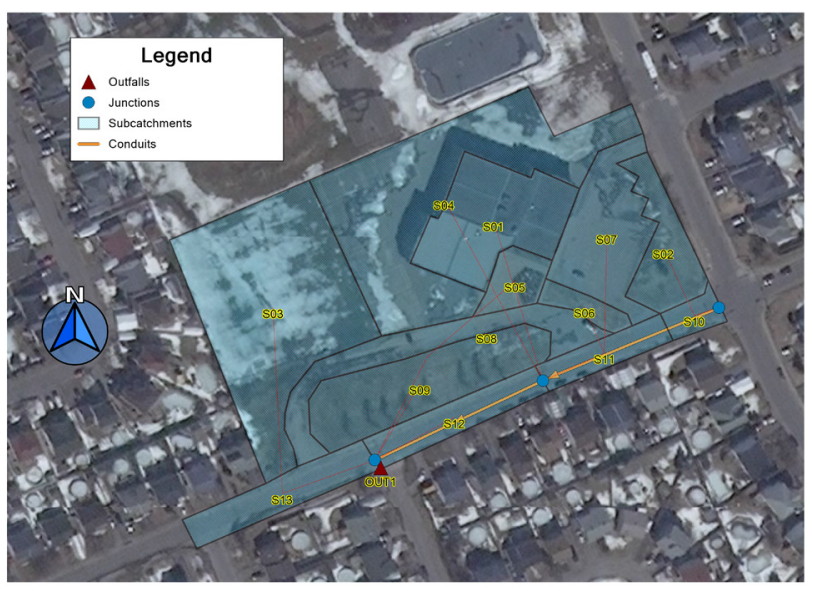

Figure 1 Watershed configuration.

Software based on the storm water management model SWMM was used to construct the hydrological model, as SWMM was used for modeling in most of the work performed around the study area (Elliot and Trowsdale 2007). In particular, PCSWMM (developed by Computational Hydraulics International) was used. Under SWMM, each subcatchment is idealized as a rectangular shape, and balanced under a nonlinear reservoir model. Once depression storage is exceeded, runoff flow is calculated using Manning's equation. Water can be lost either through infiltration or evaporation, or it can leave a subcatchment through a specified outlet leading into another subcatchment, via an outfall or into the pipe system for which hydraulic routing is used to model flow conveyance (Abi Aad et al. 2009). For this case study, street slopes were set to $2 \%$ while sports fields, playgrounds and green spaces where set to $0.5 \%$ (except for subcatchment S09, which follows the longitudinal slope of the road of $0.8 \%$ ). Manning's roughness coefficient was estimated to be 0.11 for the overland flow over impervious areas, 0.15 for the pervious areas (with depression storage depths of $2.5 \mathrm{~mm}$ and $5 \mathrm{~mm}$ respectively), and 0.014 for closed conduit flow in concrete pipes. Additionally, the Horton infiltration model was used for a type $D$ soil with initial infiltration capacity $f_{o}$ and final infiltration capacity $f_{c}$ with values of $25 \mathrm{~mm} / \mathrm{h}$ and $1 \mathrm{~mm} / \mathrm{h}$ respectively (Carvallo Aceves and Fuamba 2016). Widths for asymmetric subcatchments were calculated using Equation 1, as used by Di Modugno et al. (2015):

$$
W=\left(2-S_{k}\right) l \text { and } S_{k}=\frac{A_{2}-A_{1}}{A_{t o t}}
$$

where:

$$
\begin{aligned}
& W=\text { the subcatchment width, } \\
& I=\text { the overland flow path length, } \\
& S_{k}= \text { a skew factor, } \\
& A_{1}, A_{2}= \text { subcatchment area to either side of the overland } \\
& \quad \text { flow path, and } \\
& A_{\text {tot }}= \text { total subcatchment area. } \\
& \text { The relatively small size of the watershed made it less than }
\end{aligned}
$$
ideal for the installation of detention basins and similar end-ofpipe BMPs. On the other hand, the poor infiltration capacities ruled out most conveyance control alternatives, such as infiltration trenches and perforated pipes, favouring instead mostly BMPs for onsite control. In this case, 4 BMPs were identified to be physically suitable for implementation: green roofs (GR), rain gardens or bioretention cells (BRT), vegetative swales (SW), and pervious pavement (PP), as shown in Table 1.

Table 1 Best management practices (BMPs) for implementation.

\begin{tabular}{clc}
\hline BMP & \multicolumn{1}{c}{ Possible Locations and Comments } & Subcatchments \\
\hline GR & $\begin{array}{l}\text { An extensive-type green roof over the school's flat roof. } \\
\text { BRT }\end{array}$ & $\begin{array}{l}\text { Partial infiltration rain gardens with underdrain to be } \\
\text { installed along green areas next to the streets. }\end{array}$ \\
SW & $\begin{array}{l}\text { A dry swale could be installed along the green area } \\
\text { between the drop-off lane and the street. }\end{array}$ & \multicolumn{1}{c}{ S09 } \\
PP $\quad \begin{array}{l}\text { Pervious asphalt for partial infiltration. Locations include } \\
\text { the school parking lot, pedestrian entrance, and the drop- } \\
\text { off lane parallel to the street. }\end{array}$ & S05, S07, S08 \\
\hline
\end{tabular}

The Québec Stormwater Management Guide identifies a wide range of pollutants that need to be monitored and controlled, but pays special attention to total suspended solids (TSS) and total phosphorous (TP). The guide proposes a water-quality rain event of $25 \mathrm{~mm}$ over $3 \mathrm{~h}$ to $6 \mathrm{~h}$, which covers $\sim 90 \%$ of the annual rain events (MDDELCC 2011). Rainfall intensities were estimated using a synthetic empirical hyetograph based on the $6 \mathrm{~h}$ Soil Conservation Society (SCS) rain event, using a time interval of 5 min (Chow 1988). The resulting hyetograph is shown in Figure 2. 


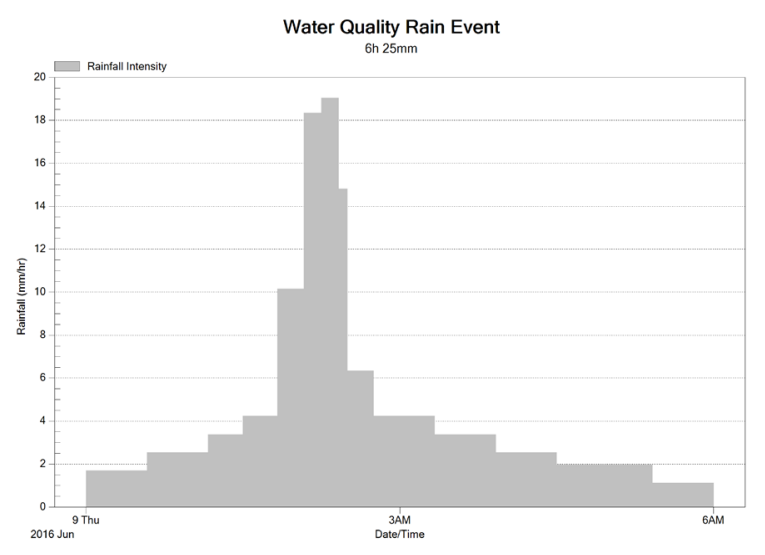

Figure 2 Rain event hyetograph.

SWMM software includes a BMP module which allows different management practices to be added to individual subcatchments. Each BMP unit is modeled as a system of layers through which the flow passes vertically, exiting the unit through a drain or as overflow, or is lost through infiltration and evaporation. The parameters used in the BMP module are summarized in Table 2, using recommended values from the literature.

Table 2 BMP modeling parameters (Carvallo Aceves and Fuamba 2016; Jato-Espino et al. 2016; James et al. 2010; MDDELCC 2011).

\begin{tabular}{|c|c|c|c|c|c|}
\hline Layer & Parameter & GR & BRT & SW & PP \\
\hline \multirow[t]{5}{*}{ Surface } & Berm Height (mm) & 5 & 250 & 100 & 2.5 \\
\hline & Vegetative Cover Fraction & 0.2 & 0.1 & 0.05 & 0 \\
\hline & Surface Roughness (Manning) & 0 & 0 & 0.3 & 0.02 \\
\hline & Surface Slope (\%) & 0 & 0 & 1.0 & 2.0 \\
\hline & Side Slope (run/rise) & - & - & 3 & - \\
\hline \multirow[t]{5}{*}{ Pavement } & Thickness (mm) & - & - & - & 100 \\
\hline & Void Ratio & - & - & - & 0.165 \\
\hline & Impervious Surface Fraction & - & - & - & 0 \\
\hline & Permeability (mm/h) & - & - & - & 36000 \\
\hline & Clogging Factor & - & - & - & 0 \\
\hline \multirow[t]{7}{*}{ Soil } & Thickness (mm) & 150 & 450 & - & - \\
\hline & Porosity & 0.453 & 0.453 & - & - \\
\hline & Field Capacity (Fraction) & 0.19 & 0.19 & - & - \\
\hline & Wilting Point (Fraction) & 0.085 & 0.085 & - & - \\
\hline & Saturated Conductivity (mm/h) & 10.92 & 10.92 & - & - \\
\hline & Conductivity Curve Slope & 7.5 & 7.5 & - & - \\
\hline & Suction Head (mm) & 110 & 110 & - & - \\
\hline \multirow[t]{4}{*}{ Storage } & Height (mm) & - & 300 & - & 400 \\
\hline & Void Ratio & - & 0.4 & - & 0.4 \\
\hline & Filtration Rate (mm/h) & - & 1 & - & 1 \\
\hline & Clogging Factor & - & 0 & - & 0 \\
\hline \multirow[t]{3}{*}{ Drainage Mat } & Thickness (mm) & 25.4 & - & - & - \\
\hline & Void Ratio & 0.33 & - & - & - \\
\hline & Surface Roughness (Manning) & 0.03 & - & - & - \\
\hline \multirow[t]{3}{*}{ Drain } & Drain Coefficient & - & 1.32 & - & 0.84 \\
\hline & Drain Exponent & - & 0.5 & - & 0.5 \\
\hline & Drain Offset Height (mm) & - & 0 & - & 0 \\
\hline
\end{tabular}

For BMP pollutant removal efficiencies, performance can vary from place to place, with different researchers obtaining a wide range of results, and with no universally agreed values (Ahiablame et al. 2012). Therefore recommended removal rates from local municipal guides, which are shown in Table 3, were used.

Table 3 BMP pollutant removal efficiencies (MDDELCC 2011).

\begin{tabular}{lcc}
\hline \multicolumn{1}{c}{ BMP } & TSS removal (\%) & TP removal (\%) \\
\hline GR & 85 & 0 \\
BRT & 80 & 50 \\
SW & 80 & 34 \\
PP & 65 & 25 \\
\hline
\end{tabular}

Pollutant accumulation and washoff must be specified for each land use in SWMM. Buildup can be modeled using power, exponential, or saturation functions, as well as through an external time series. On the other hand, washoff can be modeled using exponential functions (dependent on both the remaining pollutant mass as well as the flow), rating curves (dependent only on the flow), or through event mean concentrations (EMCs) where all the water in contact with a specific land use is attributed with the same pollutant concentration (James et al. 2010). Though the reality of pollutant transport phenomena is more faithfully represented using rating curves or exponential functions (rather than EMCs), the coefficients and variables used are site specific and require careful calibration using real data on runoff quality, as studied by Di Modugno et al. (2015).

The municipality where the case study was located expressed its interest in exploring stormwater management techniques to solve flooding and water quality issues. However, with few resources to spare for onsite measurement, no data was available on real pipe flows or pollutant concentrations. Thus pollutant washoff modeling was limited to using EMCs, with values taken from the literature, as summarized in Table 4 . A sensitivity analysis of the main hydrological parameters used is included in the discussion section of this work.

Table 4 Pollutant event mean concentrations (MDDELCC 2011).

\begin{tabular}{lccc}
\hline \multicolumn{1}{c}{ Land use cover } & Subcatchments & TSS EMC $(\mathrm{mg} / \mathrm{L})$ & TP EMC $(\mathrm{mg} / \mathrm{L})$ \\
\hline Parking lots & S07 & 58 & 0.15 \\
Low traffic streets & S08 & 86 & 0.36 \\
Medium traffic streets & $\mathrm{S} 10, \mathrm{~S} 11, \mathrm{~S} 12, \mathrm{~S} 13$ & 113 & 0.33 \\
Lawns & $\mathrm{S} 02, \mathrm{~S} 06, \mathrm{~S} 09$ & 180 & 0.4 \\
Sport fields & $\mathrm{S} 03$ & 200 & 1.07 \\
Playgrounds, driveways & $\mathrm{S} 04, \mathrm{~S} 05$ & 60 & 0.46 \\
Roofs & $\mathrm{S} 01$ & 21 & 0.13
\end{tabular}

tions of the $4 \mathrm{BMPs}$, were an and flow paths were modified accordingly. Removal rates for both pollutants were calculated by comparing the total pollutant mass at the watershed outfall from the base model with the mass from each scenario. In particular, special interest was paid to scenarios presenting combinations of BMPs where different practices were implemented in series. 


\section{Results}

The results showed that some scenarios significantly reduced pollutant mass at the outfall. Even though the main focus of this study was to analyse the impact on water quality, studying the resulting outfall hydrographs (Table 5 and Figures 3 through 5 below) remains useful as hydraulic performance goes hand in hand with pollutant removal processes.

Table 5 Simulation results for peak-flow and runoff volume.

\begin{tabular}{lccc}
\hline \multicolumn{1}{c}{ Scenario } & Peak flow $(\mathrm{L} / \mathrm{s})$ & Volume $\left(\mathrm{m}^{3}\right)$ & Runoff continuity error (\%) \\
\hline Base model & 69.85 & 375.4 & -0.139 \\
BRT & 15.38 & 248.2 & -0.189 \\
PP & 54.86 & 358.8 & -0.108 \\
GR & 59.05 & 346.7 & -0.115 \\
SW & 53.29 & 375.5 & -0.210 \\
BRT + PP & 17.70 & 261.1 & -0.164 \\
BRT + GR & 15.38 & 231.1 & -0.152 \\
BRT + SW & 15.38 & 304.6 & -0.192 \\
PP + GR & 43.35 & 330.1 & -0.085 \\
PP + SW & 59.26 & 367.3 & -0.174 \\
GR + SW & 53.01 & 348.2 & -0.157 \\
PP + GR + SW & 50.77 & 334.3 & -0.139 \\
BRT + GR + SW & 15.38 & 282.2 & -0.161 \\
BRT + PP + SW & 20.59 & 318.3 & -0.162 \\
BRT + PP + GR & 17.70 & 243.1 & -0.129 \\
BRT + PP + GR + SW & 17.70 & 290.0 & -0.128 \\
\hline
\end{tabular}

Individually (Figure 3), the 4 BMPs showed different levels of performance. Even though all practices reduced peak flows and volumes, only the swale managed to delay the peak flow, as it is the only practice providing conveyance control rather than onsite control. Rain gardens achieved the greatest reductions in peak flow and volume. This is to be expected due to their greater capacities to store water on the surface, and the consequent slow infiltration through the soil layer into the storage layer before exiting through the underdrain. The green roof showed a modest performance, mostly due to the fact that it cannot receive flow from upstream subcatchments, which greatly limits its potential impact.

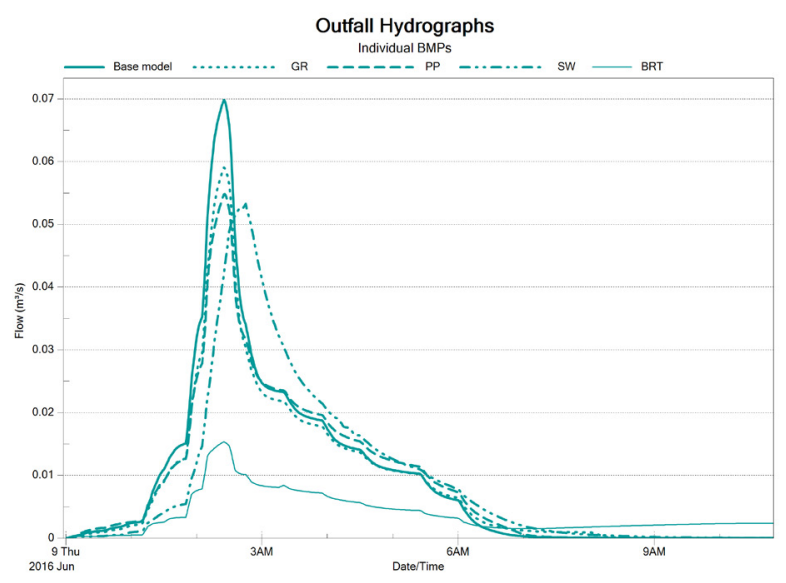

Figure 3 Outfall hydrographs (individual BMPs).
When analysing combinations of 2 BMPs (Figure 4), the results are consistent with the individual performances. Interestingly, the combination of pervious pavement with rain gardens resulted in a greater peak flow than when using the rain gardens only. A possible explanation rests on the fact that the pervious pavements were located upstream of the rain gardens, intercepting some of the flow that would otherwise go directly into the rain gardens. Due to the high permeability rates of the pavement layer, and the limited infiltration capacity of the native soil, the water intercepted by the pervious pavement would find its way quickly into the storage layer and into the underdrain. Rain gardens feed their storage layer at a slower rate, thus permitting more infiltration losses. This suggests that pervious pavements are not an ideal solution if implemented upstream of rain gardens when full infiltration is not possible.

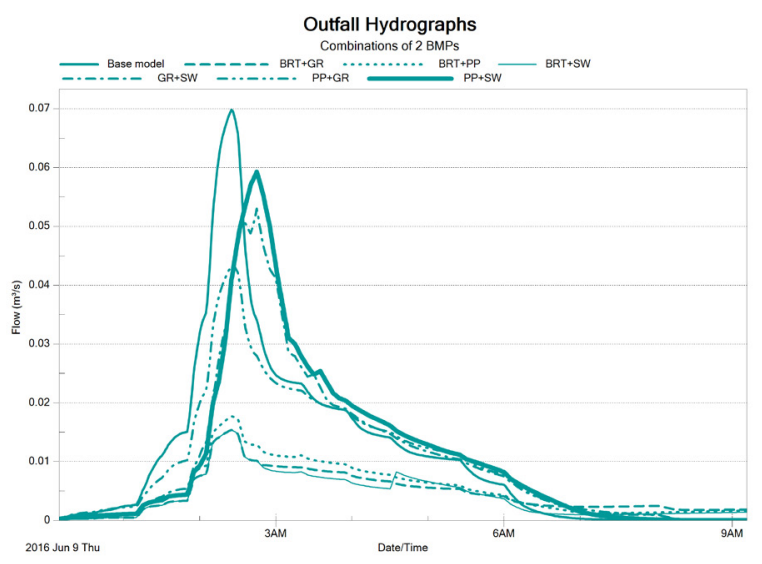

Figure 4 Outfall hydrographs (combinations of 2 BMPs).

For the combinations of 3 and 4 BMPs (Figure 5), it can be seen that the scenarios that provided the greatest reductions in volumes and peak flows were those that included rain gardens, with little difference between cases and sometimes even overlapping hydrographs, such as the BRT + PP + GR and the BRT + PP + $\mathrm{GR}+\mathrm{SW}$ scenarios. The second peak seen in some cases (e.g. BRT $+\mathrm{PP}+\mathrm{SW}$ ) could be due to the rate at which the upstream BMPs feed the downstream BMPs and the pipe network, with the first peak mostly being due to runoff coming from impervious areas. Nevertheless, and for the reasons already discussed, adding a supplementary BMP does not necessarily result in better hydraulic performance. The combination presenting the greatest reductions in runoff volume and peak flow was that of the green roof with rain gardens. It should be noted that the performance of the alternatives can also depend greatly on the chosen rain event. As the water quality scenario in this study consists of a relatively modest rain event, BMPs such as rain gardens provide great levels of control. It is entirely possible (and even expected) that other rain events would provide different levels of performance both for the individual BMPs and for the various combinations. 


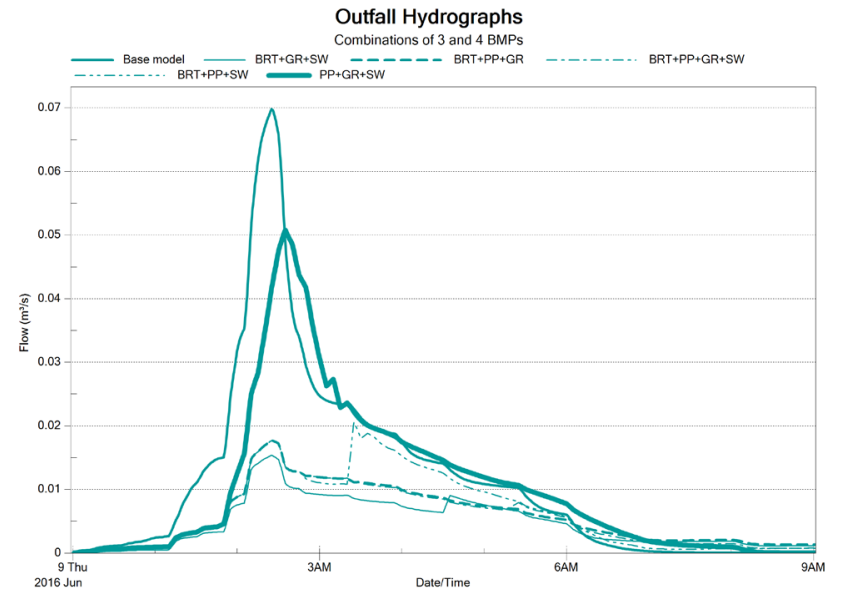

Figure 5 Outfall hydrographs (combinations of 3 BMPs and 4 BMPs).

The results for the pollutant removal rates, including the continuity errors, are shown in Table 6. The performance varies greatly between scenarios, with some even showing significant increases in pollutant mass at the outfall. The results indicate that the scenarios that include rain gardens perform better. This could be due both to the high levels of pollutant treatment that can be achieved by the BMP itself, as well as the quantitative flow control. Since all water that is infiltrated is lost, the pollutants also exit the system, so the greater the infiltration the greater the removal rates achieved. This can be verified by the fact that the scenarios which presented the greatest runoff volume reductions are also those that showed the highest removal rates. Nevertheless, it is harder to see trends in the level of water quality control achieved as the effect of the flow path itself comes into play. For instance, if a heavily polluted flow follows a longer path than the less polluted ones, it is possible that any BMP might be at full capacity when the more polluted flows finally reach it. Additionally, there are issues concerning the modeling itself. When the EMC washoff model is used in SWMM, all drops that come into contact with a particular land use will be polluted with the same specified concentration, regardless of the time span in which this occurs or how strong the flow is. This means that as the flow moves from one subcatchment to another during the rain event it will continue to pick up pollutants. For example, in the base model the roof of the school drains directly to the network, whereas in the swale scenario the same flow is forced to pass first to the drop-off lane (S08) and then into the green space (S09) before entering the swale itself. While the swale is capable of some level of treatment, the increased pollutant pickup resulted in minimal TSS removal and increased TP total discharge. This situation underlines the importance of being able to analyse the actual flow path and the placement of the BMPs, both in research work and in everyday practice. It also brings to light many of the limitations of the commonly used tools for modeling stormwater management as well as their implications, as discussed in the following section.
Table 6 Simulation results for pollutant removal rates.

\begin{tabular}{lcccccc}
\hline \multicolumn{1}{c}{ Scenario } & Mass (kg) & $\begin{array}{c}\text { TSS } \\
\text { Removal } \\
\text { rate (\%) }\end{array}$ & $\begin{array}{c}\text { Routing } \\
\text { error (\%) }\end{array}$ & Mass (kg) & $\begin{array}{c}\text { TP } \\
\text { Removal } \\
\text { rate (\%) }\end{array}$ & $\begin{array}{c}\text { Routing } \\
\text { error (\%) }\end{array}$ \\
\hline Base model & 35.624 & - & 0.202 & 0.166 & - & 0.000 \\
BRT & 20.615 & $42.13 \%$ & 0.093 & 0.083 & $50.00 \%$ & 0.000 \\
PP & 28.891 & $18.90 \%$ & 0.260 & 0.135 & $18.67 \%$ & 0.000 \\
GR & 35.588 & $0.10 \%$ & 0.206 & 0.161 & $3.01 \%$ & 0.000 \\
SW & 35.335 & $0.81 \%$ & 0.100 & 0.206 & $-24.10 \%$ & 0.000 \\
BRT + PP & 20.686 & $41.93 \%$ & 0.105 & 0.083 & $50.00 \%$ & 0.000 \\
BRT + GR & 20.603 & $42.17 \%$ & 0.109 & 0.083 & $50.00 \%$ & 0.000 \\
BRT + SW & 21.979 & $38.30 \%$ & 0.103 & 0.090 & $45.78 \%$ & 0.000 \\
PP + GR & 30.612 & $14.07 \%$ & 0.347 & 0.135 & $18.67 \%$ & 0.000 \\
PP + SW & 52.842 & $-48.33 \%$ & 0.112 & 0.250 & $-50.60 \%$ & 0.000 \\
GR + SW & 52.505 & $-47.39 \%$ & 0.123 & 0.238 & $-43.37 \%$ & 0.355 \\
PP + GR + SW & 27.895 & $21.70 \%$ & 0.124 & 0.164 & $1.20 \%$ & 0.000 \\
BRT + GR + SW & 21.902 & $38.52 \%$ & 0.115 & 0.087 & $47.59 \%$ & 0.000 \\
BRT + PP + SW & 27.263 & $23.47 \%$ & 0.110 & 0.111 & $33.13 \%$ & 0.000 \\
BRT + PP + GR & 20.612 & $42.14 \%$ & 0.132 & 0.082 & $50.60 \%$ & 0.000 \\
BRT + PP + GR + SW & 20.776 & $41.68 \%$ & 0.134 & 0.082 & $50.60 \%$ & 0.000 \\
\hline
\end{tabular}

\section{Discussion}

As mentioned above, the lack of real world data for calibration limits the accuracy of the model and validity of the results. At the same time, it also reflects the conditions under which everyday projects might be executed. A sensitivity analysis of the base model was performed on some of the key hydrological variables, namely the initial infiltration capacity, the slope and the depression storage depth. Values were modified within ranges deemed relevant for the study. For example, seeing that the watershed is fairly flat, it was more relevant to see the effect of greater slopes than smaller ones.

Figure 6 shows that the runoff volume is relatively insensitive to changes in the tested variables. Modifying the slopes of impervious areas had no effect whatsoever. This parameter could, in theory, have an impact on runoff volumes if the increased slope resulted in runoff from impervious areas reaching pervious areas more quickly. However, this was not the case for the watershed, as all impervious areas were drained either to other impervious areas or directly into the pipe system. The variable with the greatest impact was the Horton $f_{o}$ value. This is to be expected as it directly affects the losses by infiltration, but even a $100 \%$ increase in initial infiltration capacity resulted in only small changes in runoff volume.

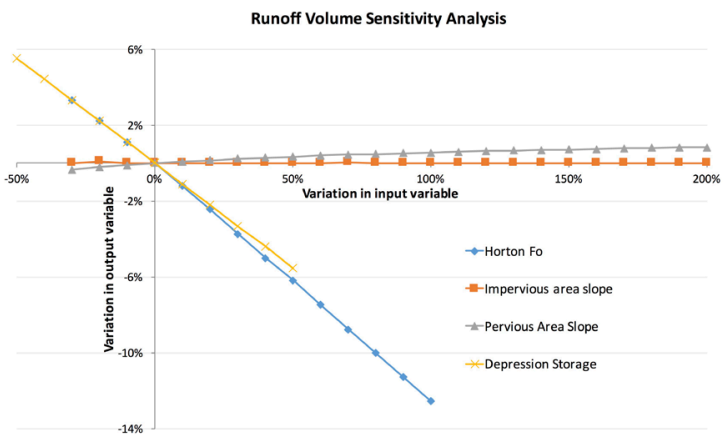

Figure 6 Runoff volume sensitivity analysis. 
In a similar way, the peak flow sensitivity analysis (Figure 7) shows relatively small changes in the output variable. Interestingly, both the depression storage depth and the infiltration capacity seemed to reach a point after which no further impact on the peak flow was observed. This can be explained by the fact that modifying the infiltration capacity only affects pervious areas, and that depression storage depth is also more significant in these areas. Increasing these two variables ultimately delays the runoff from pervious areas to the point where their contribution to the outfall peak flow arrives after the peak flow from impervious areas has occurred. As such, increasing this delay will have no further effect on the overall peak flow as it is more dependent on impervious areas.

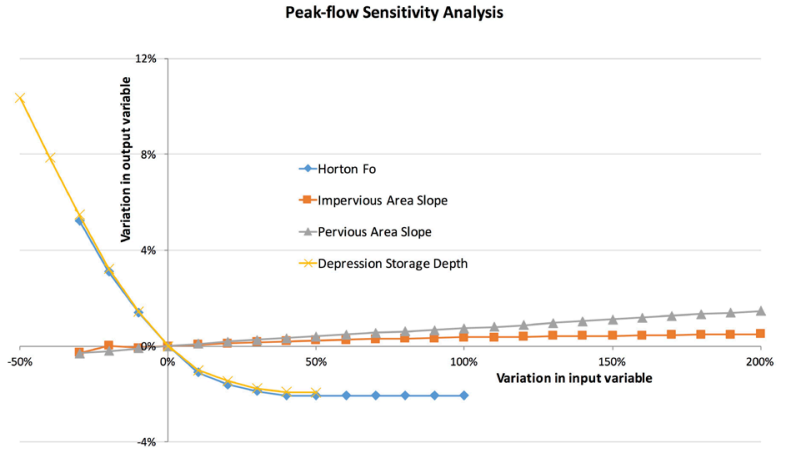

Figure 7 Peak flow sensitivity analysis.

Figures 8 and 9 show the effects of these variables on pollutant discharges. The shape of the graphs is essentially the same as the shape of the runoff sensitivity analysis graph. This is logical since EMCs were used, meaning that the total pollutant mass is directly dependent on the runoff volume. Nevertheless, the range of variations in the output variable is greater than for the runoff sensitivity analysis. This can be explained by the fact that that when runoff is reduced, it is mainly in pervious areas (by increasing infiltration losses). However, not every land use cover produces the same pollutant EMC. In this case, runoff from impervious areas was less polluted than that from pervious areas. Therefore, any reductions of runoff from the latter will result in proportionally greater reductions of pollutant discharges.

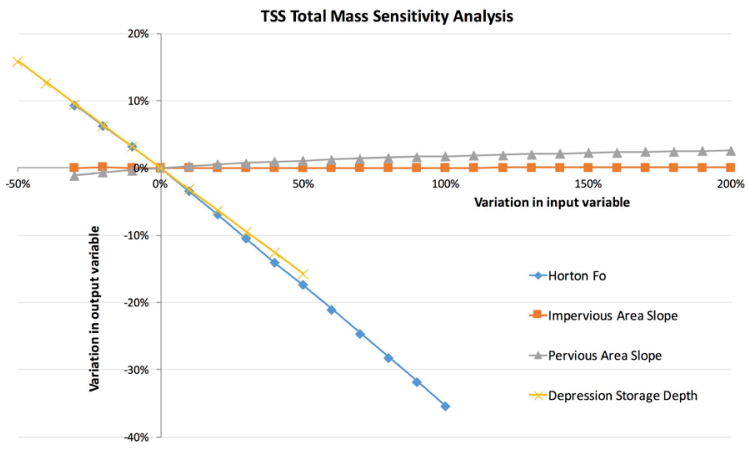

Figure 8 Total suspended solids (TSS) total mass sensitivity analysis.

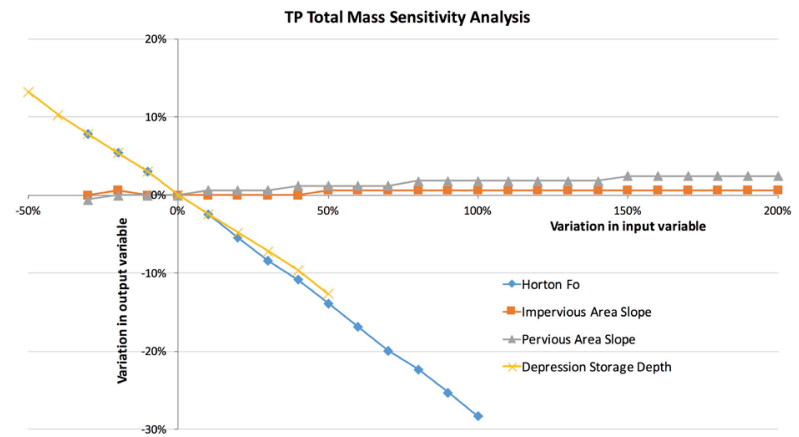

Figure 9 Total phosphorous (TP) total mass sensitivity analysis.

In light of this first sensitivity analysis, the hydrological model appeared to be reasonably adequate, indicating that some level of uncertainty in the input variables would have little effect on the relevant hydrological variables computed by the software. In order to test the effect of the BMP removal rates on the pollutant mass a second sensitivity analysis was carried out (Figure 10) using the individual BMP scenario with the greatest performance in water quality control, which was the rain garden scenario. The results of the analysis show that, even though increasing the removal rate efficiency reduces the pollutant mass, the output variable is relatively insensitive (in the case of TP the step-shaped graph can be explained by the decimal precision of the software). This would suggest that other factors contribute to reducing the total pollutant discharge, most likely infiltration losses, as infiltration is another possible way in which pollutants can leave the system. Therefore, while actual removal rates remain a subject of debate, their impact in reducing pollutant discharges might be less significant when looking at the overall hydrological model.

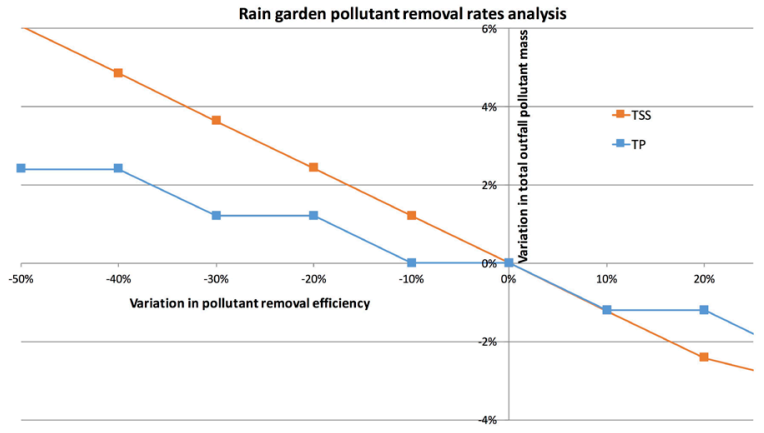

Figure 10 Rain garden pollutant removal rates sensitivity analysis.

Considering the results from the sensitivity analyses, different points can be made concerning the differences between the BMP scenarios. As mentioned above, changing the flow path along the surface can significantly affect the level of runoff pollution. While it is true that water coming into contact with various surfaces can pick up more pollutants along the way, the assumption that the process remains constant throughout the rain event, which is the case when using EMCs, is hardly realistic. Therefore, 
using more complex buildup and washoff functions seems to be necessary. Then again, the issue of data availability becomes important. Obtaining the information needed to properly model and calibrate pollutant transportation could easily become time consuming and expensive. Additionally, the data could very well change over time as land use cover changes, as do the sources of runoff pollution, which makes the problem even more complex.

Nevertheless, the results of the case study point to several important issues. In heavily urbanized watersheds, it may be easy to think that implementing as many management practices as possible would be ideal. The results presented here suggest otherwise and call for caution when developing management plans. As shown for both the water quality and quantity controls, the incremental benefits of implementing additional BMPs can be minimal or even detrimental. This reinforces the notion that a nonlinear relationship exists and that a given configuration of BMPs should be studied as a whole, and not as individual practices added together. However, it is true that BMPs could also bring other benefits unrelated to stormwater management, such as the benefits of green space or temperature regulation, as is the case of green roofs (MDDELCC 2011). Thus the installation of additional BMPs that do not contribute to runoff and quality control can hardly be called wasteful or useless in the context of a larger urban planning scheme.

As already stated, the software tools regularly used, such as SWMM, are limited in their ability to accurately model the processes necessary for stormwater management. Concepts such as irreducible concentrations, as studied by Hathaway and Hunt (2009), and the first flush phenomenon (Di Modugno et al. 2015) remain to be studied in greater depth. More information is then needed to validate the findings presented here. In particular, long term monitoring of water quality is needed in a real life setting, albeit the economic resources might be considerable and the results highly site specific. In any case, real data on large scale setups would be invaluable. Additionally, the changing levels of BMP performance should be taken into account, not only in the long term as the BMP installation ages, but also within a single rain event, as the level of pollutant treatment achieved is hardly constant over time.

Ultimately, if local governments wish to impose water quality control limits on stormwater in order to protect the receiving water bodies, the relevant personnel should have the necessary tools and information to ensure that the proposed alternatives provide the desired level of control. Nevertheless, more data is still needed as the complex processes involved seem to hinder the accurate fulfillment of this objective.

\section{Conclusions}

The implementation of stormwater BMPs could provide flow and runoff volume control in an effort to restore the hydrological cycle in a watershed, thus mitigating the negative effects of urbanization. The benefits also include water quality control, which can be achieved by reducing runoff that would otherwise carry pol- lutants into the drainage infrastructure, and by providing water remediation treatment as the flow passes through the BMPs. This work aimed to provide further study of how the levels of control provided can change as BMPs are arranged in different combinations, particularly serial configurations, by comparing outfall hydrographs and the total masses of the different pollutants. A case study of a residential watershed in the Greater Montréal area was used, in which four BMPs were modeled individually and in combination. The results reinforce the idea that infiltration plays a larger role in pollutant removal than actual treatment, as shown by those combinations that achieve the greatest reductions in runoff volume. Additionally, the model suggests that the benefits of implementing additional BMPs can be minimal and in some cases even yield a lower performance, both in purely hydraulic terms and in increasing water quality. When analyzing the hydraulic performance, it is important to consider which are the main physical processes in each BMP that contribute to flow and volume reductions and to evaluate if these could influence the performance of other BMPs downstream.

Concerning the water quality, it appears that the flow path itself could have a significant impact on pollutant discharge as runoff can potentially pick up more pollutants when flowing from one subcatchment to another on the surface if it does not directly enter the pipe network. Nevertheless, using EMCs, as was the case in the present study, may not faithfully represent the complex processes involved in pollutant transport. On the other hand, more complex models require information that is highly site specific and in some cases unavailable. This situation calls for the further development of the tools used in everyday practice, such as SWMM, as well as more research, particularly in obtaining real world data on the long term performance of various BMP combinations in order to be able to properly assess if alternatives satisfy local policies on water quality.

\section{References}

Abi Aad, M. P., M. T. Suidan and W. D. Shuster. 2009. "Modeling Techniques of Best Management Practices: Rain Barrels and Rain Gardens Using EPA SWMM-5." Journal of Hydrologic Engineering 15 (6). https://doi.org/10.1061/(ASCE)HE.19435584.0000136.

Ahiablame, L. M., B. A. Engel and I. Chaubey. 2012. "Effectiveness of Low Impact Development Practices: Literature Review and Suggestions for Future Research." Water Air and Soil Pollution 223 (7): 4253-73. https://doi.org/10.1007/s11270-012-1189-2.

Cahill, T. H. 2012. Low Impact Development and Sustainable Stormwater Management. Hoboken, NJ: Wiley.

Carvallo Aceves, M. and M. Fuamba. 2016. “Methodology for Selecting Best Management Practices Integrating Multiple Stakeholders and Criteria: Part2-Case Study." Water 8 (2): 56.

https://doi.org/10.3390/w8020056. 
Chen, L., J. Qiu, G. Wei and Z. Shen. 2015. “A Preference-Based Multi-Objective Model for the Optimization of Best Management Practices." Journal of Hydrology 520:356-66. https://doi.org/10.1016/j.jhydrol.2014.11.032.

Chow, V. T., D. R. Maidment and L. W. Mays. 1988. Applied Hydrology. New York: McGraw Hill Science.

Dai, C., Y. P. Cai, W. Ren, Y. F. Xie and H. C. Guo.2016. “Identification of Optimal Placements of Best Management Practices Through an Interval-Fuzzy Possibilistic Programming Model." Agricultural Water Management 165:108-21. https://doi.org/10.1016/j.agwat.2015.10.016.

DEP (Pennsylvania Department of Environmental Protection). 2006. Stormwater Best Management Practices Manual. Harrisburg, PA: Pennsylvania Department of Environmental Protection. http://www.elibrary.dep.state.pa.us/dsweb/View/Collection-8305.

Di Modugno, M., A. Gioia, A. Gorgoglione, V. lacobellis, G. la Forgia, A. F. Piccini and E. Ranieri. 2015. “Build-up/Wash-off Monitoring and Assessment for Sustainable Management of First Flush in an Urban Area." Sustainability 7 (5): 5050-70. https://doi.org/10.3390/su7055050.

Elliot, A. H. and S. A. Trowsdale. 2007. "A Review of Models for Low Impact Urban Stormwater Drainage." Environmental Modeling and Software 22 (3): 394-405. https://doi.org/10.1016/j.envsoft.2005.12.005.

Fuamba, M., C. Coulais and H. Bertrand. 2011. “An Innovative Method for Selecting Efficient Best Management Practices." In Proceedings of the 12th International Conference on Urban Drainage, Porto Alegre, Brazil.

GVSDD (Greater Vancouver Sewerage and Drainage District). 1999. Best Management Practices Guide for Stormwater. Vancouver, BC: Greater Vancouver Sewerage and Drainage District.

Hathaway, J. M. and W. F. Hunt. 2009. “Evaluation of Stormwater Wetlands in Series in Piedmont, North Carolina." Journal of Environmental Engineering 136 (1): 140-6. https://doi.org/10.1061/(ASCE)EE.1943-7870.0000130.

Jia, H., H. Yao, Y. Tang, S. L. Yu, J. X. Zhen and Y. Lu. 2013. “Development of a Multi-Criteria Index Ranking System for Urban Runoff Best Management Practices (BMPs) Selection." Environmental Monitoring and Assessment 185 (9): 7915-33. https://doi.org/10.1007/s10661-013-3144-0.
James, W., L. A. Rossman and W. R. C. James. 2010. User's Guide To SWMM 5. Guelph: CHI Press.

Jato-Espino, D., S. M. Charlesworth, J. R. Bayon and F. Warwick. 2016. "Rainfall-Runoff Simulations to Assess the Potential of SuDS for Mitigating Flooding in Highly Urbanized Catchments." International Journal of Environmental Research and Public Health 13 (1): 149. https://doi.org/10.3390/ijerph13010149.

Maringanti, C., I. Chaubey, M. Arabi and B. Engel. 2011. "Application of a Multi-Objective Optimization Method to Provide Least Cost Alternatives for NPS Pollution Control." Environmental Management 48 (3): 448-61. https://doi.org/10.1007/s00267-011-9696-2.

Martin, C., Y. Ruperd and M. Legret. 2007. “Urban Stormwater Drainage Management: The Development of a Multicriteria Decision Aid Approach for Best Management Practices." European Journal of Operational Research 181 (1): 338-49. https://doi.org/10.1016/j.ejor.2006.06.019.

MDDELCC (Ministère du Développement durable, de l'Environnement et de la Lutte contre les changements climatiques). 2011. Stormwater Management Guide. Québec: Ministry of Sustainable Development, the Environment and the Fight Against Climate Change.

Sebti, A., M. Carvallo Aceves, S. Bennis and M. Fuamba. 2016. "Improving Nonlinear Optimization Algorithms for BMP Implementation in a Combined Sewer System." Journal of Water Resources Planning and Management 142 (9). https://doi.org/10.1061/(ASCE)WR.1943-5452.0000669.

TRCA (Toronto and Region Conservation Authority). 2010. Low Impact Development Stormwater Management Planning and Design Guide. Toronto: Toronto and Region Conservation Authority.

Zou, R., J. Riverson, Y. Liu, R. Murphy and Y. Sim. 2015. “Enhanced Nonlinearity Interval Mapping Scheme for High Performance Simulation-Optimization of Watershed-Scale BMP Placement." Water Resources Research 51 (3): 1831-45. https://doi.org/10.1002/2014WR015772. 